Home (http://halduskultuur.eu/journal/index.php/HKAC/index)

/ Archives (http://halduskultuur.eu/journal/index.php/HKAC/issue/archive)

/ Vol 20 No 1 (2019): General Issue

(http://halduskultuur.eu/journal/index.php/HKAC/issue/view/26)

/ Articles

\title{
Examining the Collaborative Process: Collaborative Governance in Malaysia
}

PDF (http://halduskultuur.eu/journal/index.php/HKAC/article/view/211/174)

Published Nov 11, 2019

DOI https://doi.org/10.32994/hk.v20i1.211 (https://doi.org/10.32994/hk.v20i1.211)

\author{
Abdillah Noh, Dr \\ International Islamic University Malaysia \\ Nadia Hezlin Yashaiya \\ University of Western Australia
}

\section{Abstract}

This article identifies and examines factors important to the collaborative process. It does so by treating Malaysia's performance and management delivery unit (PEMANDU) - which is an agent that played a central role in economic and government transformation programmes - as a prism from which to identify essential components of collaboration. By examining PEMANDU's various initiatives together with descriptions of two cases on collaboration, the article concludes that facilitative leadership and one-of-a kind organizational design are necessary but not sufficient conditions for a successful collaborative-governance endeavor. Institutionalizing collaborative governance remains problematic. This is because even though collaborative governance is nested within the country's larger development concerns, the issues of trust, legitimacy and regime change have made collaborative governance a still nascent tool for public-sector reform effort.

Issue

Vol 20 No 1 (2019): General Issue (http://halduskultuur.eu/journal/index.php/HKAC/issue/view/26) 
Articles

Author Biographies

\section{Abdillah Noh, Dr, International Islamic University Malaysia}

Abdillah Noh is an Associate Professor at the Department of Political Science, International Islamic University Malaysia (IIUM). He works in the areas of institutional change, public administration and public policy. Abdillah has a DPhil (Politics) from St Antony's College, University of Oxford.

\section{Nadia Hezlin Yashaiya, University of Western Australia}

Nadia Yashaiya is a PhD candidate at the University of Western Australia. Her research focuses on public management, with an emphasis on employee job motivation, socialisation and public service motivation.

Current Issue

\begin{tabular}{|l|l|}
\hline ATOM & 1.0 \\
\hline
\end{tabular}

(http://halduskultuur.eu/journal/index.php/HKAC/gateway/plugin/WebFeedGatewayPlugin/atom)

\section{REs 2.0}

(http://halduskultuur.eu/journal/index.php/HKAC/gateway/plugin/WebFeedGatewayPlugin/rss2)

\begin{tabular}{|l|l|l|l|l|l|}
\hline Rss & 1.0 \\
\hline
\end{tabular}

(http://halduskultuur.eu/journal/index.php/HKAC/gateway/plugin/WebFeedGatewayPlugin/rss)

Information

For Readers (http://halduskultuur.eu/journal/index.php/HKAC/information/readers)

For Authors (http://halduskultuur.eu/journal/index.php/HKAC/information/authors)

For Librarians (http://halduskultuur.eu/journal/index.php/HKAC/information/librarians)

Open Journal Systems (http://pkp.sfu.ca/ojs/) 


\title{
Examining the Collaborative Process: Collaborative Governance in Malaysia
}

ABDILLAH NOH, INTERNATIONAL ISLAMIC UNIVERSITY MALAYSIA, DEPARTMENT OF POLITICAL SCIENCE, MALAYSIA.

NADIA YASHAIYA, UNIVERSITY OF WESTERN AUSTRALIA, DEPARTMENT OF POLITICAL SCIENCE, AUSTRALIA.

\begin{abstract}
This article identifies and examines factors important to the collaborative process. It does so by treating Malaysia's performance and management delivery unit (PEMANDU) - which is an agent that played a central role in economic and government transformation programmes - as a prism from which to identify essential components of collaboration. By examining PEMANDU's various initiatives together with descriptions of two cases on collaboration, the article concludes that facilitative leadership and one-of-a kind organizational design are necessary but not sufficient conditions for a successful collaborative-governance endeavor. Institutionalizing collaborative governance remains problematic. This is because even though collaborative governance is nested within the country's larger development concerns, the issues of trust, legitimacy and regime change have made collaborative governance a still nascent tool for public-sector reform effort.
\end{abstract}

Keywords: Collaborative Governance; Collaborative Process; Delivery Unit; PEMANDU; Malaysia

\section{Introduction}

Collaborative governance is increasingly viewed and adopted by governments as a possible remedy to address various bureaucratic concerns. The recursive and iterative nature of the collaborative process and the promotion of horizontal and vertical integration in collaborative governance are viewed as essential qualities for bureaucracy to deliver the public good as well as navigate the close nexus between politics and administration (Meier and Bohte 2007). Collaborative governance is also increasingly seen as the best method for bureaucrats to overcome rigid adherence to traditional axioms of implementation (Hill and Hupe 2014), especially at a time when public policy demands quick and effective policy delivery. Collaborative governance is also associated with the ideas of adaptability and flexibility, two qualities that are viewed as capable of producing better policy design and execution (Thomson et al. 2007: Ansell et al. 2017).

Besides facilitating public-policy delivery, collaboration is also seen as encouraging democratic governance. Collaboration can act as a powerful tool to resolve a dispute and empower participatory governance (Fung 2004; Fung et al. 2003). Collaboration is also found to be an effective tool to overcome adversarial democracy and for the state to reclaim its administrative trust and legitimacy (Newman et al. 2004; Innes and Booher 1999; Ansell and Torfing 2014; Sabel and Zeitlin 2008; Dorf and Sabel 1998). 
But despite the qualities of collaborative governance, identifying the collaborative process is highly problematic. Gaining access to the collaborative process is difficult, especially when bureaucracy is highly impermeable to outsiders. Wood and Gray (1991) describe the collaborative process as a "black-box", where gaining access to collaborative factors remains difficult and challenging for outside observers. Identifying factors that go into a collaborative process is also onerous because they do not come in neat packages given various factors like the nature of the bureaucracy, leadership, the near opaqueness of the process and the iterative nature of policy formulation (Meier and Bohte 2007). While identifying and examining factors in a collaborative process remains a challenge, this paper takes the view that one best way to understand the collaborative process is to adopt a second-best approach, that is by treating an agency - which is involved or tasked to promote the state's administrative reform effort - as a prism from which to identify and examine factors that contribute to a collaborative process. This paper will do so by examining the operation of a significant change agent in Malaysia, the Performance and Management Delivery Unit (also called PEMANDU). PEMANDU was a change agent that was tasked with instituting Malaysia's economic and government transformation programs. Besides examining PEMANDU's organizational design and operations the article will also highlight two case studies - which PEMANDU was involved in - to shed further light on the collaborative process.

The effort to understand the collaborative process and collaborative governance is also timely because collaborative governance is relatively new in non-Western contexts. Work on collaborative governance in Malaysia is rather limited, perhaps due to the newness of the idea. Up until now, there has been one work that discusses this - and a very recent one at that. Using Ansel and Gash's (2008) collaborative governance framework, Ramadass et al. (2018) identified transformational leadership, governance, and relational capital as important to collaborative success. This work is important as it highlights the significance of leadership and relational capital in collaborative governance. The work, however, does not provide specifics on the collaborative process. Other than highlighting that leadership and relational capital are statistically significant, it does not describe the extent to which leadership and relational capital operate within a particular institutional structure. Also it does not discuss the nature of organizational design and how it can facilitate collaboration. The work also does not elaborate on the dynamics of leadership or describe issues of trust, legitimacy, and reciprocity that may be essential for a more complete picture of collaboration. This paper hopes to address these concerns. Using interviews and case studies the paper will provide a thick description to highlight the relevance of institutional design, trust, leadership, shared motivation and how they operate within idiosyncratic conditions. It will address the following questions. First, what is the nature and extent of Malaysia's collaborative governance design? Second, what are the distinctive features of the collaborative process? Finally, what are the factors that contribute to the workability or unworkability of the collaborative process?

We obtained data from various sources. The sources include PEMANDU annual reports, various reports on PEMANDU conducted by the World Bank and other secondary materials like published articles and newspaper write-ups. We also conducted five interviews with people who have worked closely with PEMANDU. Two of them are very senior officers in the bureaucracy. One officer was directly involved with PEMANDU when she was seconded to it. Another was a high-ranking senior official who on various occasions had direct dealings with PEMANDU. As for the two other experts, one was a special officer in a ministry who had the opportunity to be involved in lab sessions conducted by PEMANDU. The other was one of the 
few officers who had the opportunity to see how PEMANDU was first set up. This expert gave a detailed account of the early days of PEMANDU and its objectives. One of the authors also had the chance to chat with a prime officer of PEMANDU at one social event. During the chat, the officer gave a brief but important insight on PEMANDU. He gave a philosophical insight to PEMANDU and highlighted how PEMANDU's organizational design and collaborative processes had been adopted in many countries outside of Malaysia. Indeed, the interviews highlighted some major issues confronting PEMANDU. They were helpful as they gave clarity to the case studies as well as the secondary reports and highlighted conceptual terms that are important to collaborative governance, such as trust, legitimacy, resources, leadership and institutional design.

The paper is divided as follows. The first part will provide various definitions and discussions on collaborative governance. The next part will discuss the role of PEMANDU and how its various processes have unintentionally laid down the importance of collaborative governance in the Malaysian bureaucracy. The third part of the paper will describe the two case studies. The fourth part of the paper will provide brief discussions of the findings on collaborative governance.

\section{Collaborative Governance and Collaborative Process}

With rapid technological advancement and increasing social complexities, it has become increasingly difficult, perhaps even impossible, for bureaucracies to operate within information silos and deliver agency-centric policies. Not many scholars were initially convinced that a collaborative model of governance can deliver better public good. Bardach (1998) emphasizes that collaboration can only be useful if it "produces better organizational performance or lower costs that can be had without it."(Bardach 1998, 17). But the rapid advancement in information technology, scarce resources and the wicked nature of policy problems increasingly demand a multidisciplinary approach to public policy, which saw collaborative governance gaining traction as an attractive administrative tool. Collaborative governance is seen as a response to the rise of "permeable structures", one where people are linked across organizational functions and boundaries (McGuire 2006).

There are many definitions of collaborative governance. It is largely described as an integrative exercise involving various parties. The difference between the many definitions of collaborative governance lies in the qualification of actors involved in the collaborative process. Gray (1998), for instance, defines collaborative governance as an integrative exercise where "parties who see different aspects of a problem can constructively explore their differences and search for solutions that go beyond their own limited vision of what is possible" (Gray 1998, 5). Emerson et.al $(2012,2015)$ gave a broader and more inclusive definition, describing collaborative governance as one that involves "processes and structures of public policy decision making and management that engage people ... across the boundaries of public agencies, levels of government, and/or the public, private and civil spheres to carry out a public purpose that could not otherwise be accomplished.. Ansell and Gash (2008), however, provide a narrower definition, describing collaborative governance as an "arrangement where one or more public agencies directly engage non-stakeholders in a collective decision-making process that is formal or consensus-oriented and deliberative and that aims to make or implement public policy or manage public programs or assets" (Ansell and Gash 2008, 544). We find this definition to fit the Malaysian case. Its reference to collective decision-making, consensus, 
deliberation and the formal nature of the collaborative process is highly relevant to Malaysia, a plural polity where policies have always been a product of intense negotiation, compromises, and consensus.

But a more central concern of this study is the collaborative process. Wood and Gray (1991) argue that while there are many discussions on antecedents and outcomes of collaboration, there is little explanation on the "process" segment of collaborative governance. They argue the need to be attentive to the collaborative process, arguing the importance of administration, government, organizational autonomy, mutuality and norms of trust and reciprocity. Ring and Van de Ven (1994) added to Wood and Gray's (1991) explanation, describing the collaborative process as cyclical and iterative in nature. They also pose a caveat stating that the non-linear and unstructured qualities of the collaborative process could inadvertently pose a challenge to policy implementers and decision-makers. Since the work of Wood and Gray (1991) there have been more efforts at identifying essential qualities of the collaborative process. Besides understanding formal structures, evaluating collaborative processes also requires understanding informal structures (Thomson and Perry 2006). Some of these considerations include factors like commitment, communication, and trust (Huxham and Vangen 2000a), as well as leadership and governance (Currie et al. 2011; Hui et al. 2011; Siddiquee 2007). While getting insights into informal structures in collaborative transactions is indeed a challenge, it is necessary because variables like personal relationships, psychological contracts and informal understanding and commitment of different stakeholders can provide a more complete insight into delivery-level behavior (Thomson and Perry 2006, 22). Thomson et al. (2007) also give a more elaborate explanation of the collaborative process saying that it involves five important elements - governance, administration, organizational autonomy, mutuality and norms of trust. In coming up with their collaborative governance model, Ansell and Gash (2008) give centrality to the collaborative process, emphasizing the importance of variables such as trust, mutual recognition, participatory inclusiveness as well as leadership styles. They also highlight the importance of institutional design as well as starting conditions like political, legal, socio-economic features, leadership and bureaucratic environment (Ansell and Gash 2008). More recently, Emerson et al. (2012) produced an equally comprehensive model of collaborative governance that gives further insight into the variables that are important when examining the collaborative process. Called the integrative framework, the model pivots on the need to understand the system context - political, legal, socioeconomic - as well as other essential issues like leadership, incentives, and interdependence. The model also highlights the need to understand the "sets of implicit and explicit principles, rules, norms, and decision-making procedures around which actors' expectations converge in a given area" (Emerson et al. 2011, 5).

The above discussions on collaborative governance gave important insights into the variables that one needs to look out for when examining the collaborative process. Identifying the variables that go into a collaborative process, however, is indeed a challenge given the near impermeability of the bureaucratic processes. The process is made more challenging when we take into account countries' different political, socio-economic and legal environments. If you are an outsider with no access to core people in the bureaucracy, the near opaqueness and impermeability of the bureaucratic process can make examining the collaborative process even more difficult. Recognizing such difficulty we have attempted to understand the collaborative process by using a second-best approach. We chose PEMANDU because it incorporated a collaborative approach in its numerous projects and hence provided us the 
prism from which to understand processes and elements that are essential to the collaborative process. We now describe PEMANDU.

\section{About PEMANDU}

PEMANDU (the Performance Management and Delivery Unit) was established in 2009. The inspiration for having a delivery unit came from the United Kingdom's Prime Minister Delivery Unit (PMDU). PEMANDU was part of the state's effort to promote better accountability, legitimacy and governance following the then ruling regime's heavy defeat in the 2008 general election, where it won the election but secured less than two-thirds of total parliamentary seats. In its design, PEMANDU was not a typical public agency. It was a pseudo-public organization that did not conform to the general operational standards of other agencies within the Malaysian bureaucracy. Unlike other government agencies, PEMANDU did not come under the direct control of the head of the civil service, which is the chief secretary to the government, but rather under the direct charge of the Prime Minister. This arrangement - which will be explained below - allowed PEMANDU the autonomy to recruit personnel, the ability to plan for its own budget and the ability to have direct access to the Prime Minister. PEMANDU offered the facilitative leadership required of a collaborative process. By facilitative leadership we mean the ability to bring various stakeholders together and get them to engage in a collaborative spirit (Ansell and Gash 2008; Chrislip and Larson 1994; Reilly 1998). Such leadership involves exercising a number of functionalities, which include maintaining the ground rules, building trust and facilitating dialog between stakeholders (Ansell and Gash 2008, 544). There are also those that describe facilitative leadership as one that embraces, empower, mobilize stakeholders (Ansell and Gash 2008; Vangen and Huxham 2000a, 2003). One description that bears close proximity to PEMANDU's role is Ryan's (2001) definition that an effective collaborative leader must have three essential components: adequate management of the collaborative process; maintaining "technical credibility; ability to empower different stakeholders to make credible and convincing decisions that are acceptable to all" (Ryan 2001, 241).

But unlike Ansell and Gash's (2008) elaboration of what constitutes facilitative leadership, PEMANDU's leadership role had an added dimension. It was given a broad mandate; assuming the role of a facilitative leader as well as taking charge of delivering the state's economic and government transformation programs. PEMANDU's positioning in the Malaysian bureaucracy reflects this broad mandate; a position in the hierarchy that was unprecedented in Malaysia's administrative reform history. It was a unit within the Malaysian bureaucracy, yet it did not exactly operate like other agencies within the bureaucracy. For instance, despite it being an administrative unit under the Prime Minister Office - PEMANDU's Chief Executive Officer reported directly to the Prime Minister and not to the head of the Malaysian civil service, the Chief Secretary of State. In its operation, PEMANDU was given the flexibility to manage its resources. PEMANDU had its own human-resource department, which was in charge of hiring and talent management. About 80 percent of PEMANDU's officers came from the private sector. These officers were given remuneration packages that were different from the ones enjoyed by other civil servants. Structure-wise, PEMANDU had several divisions, with each division taking charge of a particular NKRAs. Each division was headed by a director. When it came to reporting, PEMANDU'S CEO reported directly to the Prime Minister and not to the chief secretary of the civil service (Xavier et al. 2016). This ministerial appointment lent him the legitimacy and gravitas to advise other ministers. In sum, even though it operated in the 
public-sector realm, PEMANDU was an autonomous unit, just like a unit that operates within the private-sector space. The idea of having a delivery unit that lies outside the mandate of the civil service is indeed a departure from Malaysia's previous administrative reform efforts.

It is not surprising that PEMANDU's unique organizational positioning plus its broad mandate and special access to the highest chief executive, the Prime Minister, invited a mixture of envy and skepticism from civil servants. One strong criticism by civil servants was that PEMANDU only added to a bloated bureaucracy. All the senior civil servants we approached said that PEMANDU's role was duplicitous to that of other prominent agencies. These officers defended their views justifying that the civil service had equally competent officers who were able to carry out the tasks mandated to PEMANDU and at a much cheaper cost. They added that there were existing agencies that were equal to the tasks that PEMANDU was delivering - agencies like the Economic Planning Unit (EPU), the Ministry of Finance, the Malaysian Administrative and Modernisation Planning Unit (MAMPU) and the Implementation and Coordination Unit (ICU). In response to the criticisms, PEMANDU's chief executive Idris Jala made known that PEMANDU was not duplicating the roles of any government agencies. In trying to appease his critics, Idris reiterated that PEMANDU merely served as a facilitator to coordinate efforts to realize the government transformation plans and that its life span was fixed. Also, the criticism against PEMANDU carries little merit because PEMANDU could be a response to a publicservice delivery problem. The bureaucracy's strict adherence to the civil service code, for example, could somehow work against collaborative tendencies. There is also every possibility that the existing structure of the bureaucracy will continue to see agencies working in silos. Indeed, the bureaucracy needed a fresh injection of new ideas and PEMANDU's design and its organizational positioning within the bureaucracy gave it the capacity to be an active agent of collaboration - one that other agencies in the bureaucracy might find hard to emulate.

Regardless, the importance of collaboration was heavily built into PEMANDU's operational design. To facilitate the collaborative tendency in the bureaucracy, one of PEMANDU's major steps was to win over the confidence of political masters and bureaucrats. One method that PEMANDU adopted to make bureaucrats and political executives accept the merit of collaboration was to involve cabinet ministers in co-creating policy design. We discuss this next.

\section{Winning over key actors}

One of the key highlights of PEMANDU initiatives was in organizing a workshop that involved cabinet ministers. The workshop was an important foundation of PEMANDU's role as a collaborative agent. By having this workshop PEMANDU achieved two things; first it promoted buy-ins from cabinet ministers to PEMANDU's various initiatives and second, the workshop forged inter-ministerial cooperation, a feature that is important in the collaborative process.

Convincing cabinet ministers of the merits of the workshop was difficult but necessary; without the buy-ins from the minister, PEMANDU would face stiffer resistance from the bureaucracy in running its programs. During the workshop, the cabinet ministers were asked to map a comprehensive plan and identify key areas that could improve public-service delivery. At the start of the workshop, obtaining buy-ins from cabinet ministers was a huge challenge; the ministers, understandably, were not convinced of the value of the collaborative project and how issues relating to one ministry could be tied to other ministries. To help ease the 
process, PEMANDU provided facilitative leadership. PEMANDU officials provided the ministers with information obtained from surveys and dialog sessions to help them have a firmer grasp of the issues. With the aid of such information, ministers were then cajoled by consultants to look beyond their individual ministry's concerns and identify critical policy concerns and goals that cut across ministries. To facilitate collaborative tendencies the conveners asked the ministers to employ a "backward" strategy when evaluating policy issues. Such a backward strategy required participants to first identify policy goals and then to work backward and search for ways that could best achieve the policy goals. The backward strategy intuitively nudged the ministers into designing a collaborative solution because it induced participants to look at issues from various dimensions for optimal policy solutions.

Another highlight of the workshop was the heavy presence of the prime minister. Such presence was helpful as it sent a signal to ministers on the seriousness of the workshop and the need for greater collaboration. The presence of the chief executive was especially helpful considering Malaysia's bureaucratic culture, where there is deference for authority and high power distance. Indeed the heavy presence of the prime minister underlined the seriousness of the collaborative project that could well help encourage reciprocal commitment from cabinet ministers.

PEMANDU understood the Malaysian bureaucratic structure and employed a tool that best responds to such a culture. The Malaysian bureaucratic culture is seen as high on collectivism (Hofstede 1980), one in which bureaucrats tend to display in-group cohesiveness, collective distribution of resources and collective action (Kennedy and Mansor 2000). There could also be the tendency for group members to exercise "perverse equalitarianism", where members tend to forego openness and keep to a conformist culture because being too direct or forthright is seen as insensitive or rude. To overcome such possible infringement to collaborative tendency, PEMANDU introduced a "blind" voting system, where new ideas - which were initially raised and deliberated - were put up for blind voting. This method safeguarded confidentiality, overcame self-censorship, helped elevate policy choices that are most in need of attention and highlighted the collaborative imperative (Iyer 201la). The "blind voting system" - which was executed during the cabinet ministers' workshop - was one among the process designs that PEMANDU employed to promote the collaborative process.

By the end of the six-week-long workshop, the cabinet ministers began to buy into the idea of collaboration; the ministers began to appreciate that the change agenda cut across the ministries. One evidence of this was when the ministers became champions of PEMANDU's numerous social labs that involved multiple stakeholders. When asked to submit officers to attend PEMANDU's various social labs, the ministers asked department heads of respective ministries to send their very best officers. The ministers sanctioned those laboratories and on occasion attended the lab sessions. There were other designs that PEMANDU introduced in order to facilitate the collaborative process. We turn to this below.

\section{Designing the collaborative process}

To settle disputes and resolve bottleneck issues on agreed-upon policies, PEMANDU designed mechanisms that incorporated elements of collaboration while at the same time taking into account Malaysia's bureaucratic culture. One of the first initiatives was setting up the Delivery Management Offices (DMOs), which are housed in each ministry. The DMOs act as 
coordinating agencies to ensure the delivery of the National Key Results Areas (NKRAs) as planned. The NKRAs were 7 socio-economic issues that needed immediate attention for Malaysia's development, and they included: reducing crime; fighting corruption; improving urban transport; raising the income of low-income households; improving rural infrastructure; improving student outcomes; and addressing cost of living. The DMOs acted as the first touchpoint in settling bottleneck issues that arose as a result of competing interests or due to institutional constraints. And, in true collaborative mode, the DMOs are made up of PEMANDU officials as well as officials from the various Ministries, Departments, and Agencies.

Besides DMOs, PEMANDU also designed administrative layers to escalate outstanding issues that are heavy in collaborative elements. Issues that remain unresolved by DMOs were first brought to a technical working group for resolution. This working group mainly comprised members from the leading ministry and members from institutions relating to the issue with PEMANDU assuming the advisory role. Should the problem remain unresolved, the issue would then be brought to a steering committee comprising relevant ministers, secretaries-general, directors-general and CEOs from important ministries and agencies. Unresolved issues were also brought to the Prime Minister in his meetings every seven weeks (one week each for one NKRA), and this meeting included the minister in charge of the NKRA, the prime minister and PEMANDU'S CEO. If the issue still remained unresolved, the matter would be brought to the Problem-Solving Meeting (PSM). The World Bank report suggests that this meeting was held twice a year and was chaired by the Prime Minister. We cannot confirm the exact timing of these six-eye meetings (Minister concerned, Prime Minister and CEO of PEMANDU), but usually the issues would be resolved at the steering-committee stage; only rarely was the issue brought to the PSM (World Bank 2017).

We must add that one feature of PEMANDU's dispute or debottlenecking mechanism is taking into consideration Malaysia's bureaucratic culture, a culture that is not naturally predisposed to inter-ministerial collaboration. PEMANDU had to negotiate serious issues of group dynamics among bureaucrats - e.g. "face-saving" or members' avoidance of group conflict. This feature of group dynamics was well understood by PEMANDU's CEO, Idris Jala. When he chaired meetings, Idris ensured that PEMANDU officials played a non-intrusive role. To get people to think of solutions, Idris drove the message to participants that the solution to issues were already there with them, reiterating that "the good ideas are already there, and people know these ideas, but the reasons we don't move from ideas to results is because there are technical, political, administrative, process, system hurdles" (Iyer 2011, 9). In essence, PEMANDU understood the group dynamics and merely nudged participants to resolve issue using their collective resources.

To make for better monitoring of projects, meetings every week, every month as well as twice yearly were organized, and these meetings were chaired by the Prime Minister. The weekly meetings - involving each of the NKRA team, delivery management office staff and other key members of the delivery chain - were meant to enable team members to be on the same page when it comes to outstanding issues and goals. The twice-yearly meeting included a six-eye meeting involving the Prime Minister, the minister leading the specific project and Idris Jala, PEMANDU'S CEO. In such meetings, the progress was reviewed using data compiled by DMOs. A dashboard system was employed, where project performances were assessed using a green, yellow and red rating; with green signaling that progress has been made while red signifies the opposite. The meetings acted as important tools to consolidate the collaborative framework, monitor the progress made and iron out outstanding issues. In commenting on 
the meetings, one PEMANDU officer said that "although PEMANDU engages with the ministries on a daily basis, these weekly problem-solving meetings with the higher management and the monthly sessions with the PM meant that little would fall through the cracks" (lyer 2011, 10).

To sum up, the design of PEMANDU's delivery process portrayed the many challenges as well as the idiosyncratic techniques used to promote collaborative governance. One important lesson is that PEMANDU's design of the collaborative framework took into account Malaysia's institutional quality, one that is characterized by a high disposition toward silo thinking, high power distance, collective thinking, perverse equalitarianism, and bureaucrats' non-confrontational disposition. There was another tool that PEMANDU employed in the collaborative process. We discuss this next.

\section{PEMANDU, collaborative design, and Social labs}

The establishment of PEMANDU's social labs - as part of its "eight-step transformation programme" - demands attention. The social labs were intended to translate the broad targets spelled out in the NKRAs - aimed at operationalizing the National Key Result Areas (NKRAs) - into concrete projects (World Bank 2017). The social labs drew officers from various ministries and agencies. These officers were handpicked and deemed to be the best of their cohorts. They were selected by cabinet ministers - who at this point bought into the idea of collaboration. In fact the ministers gave clear orders to various agencies to send their best officers to participate in the lab sessions.

The lab sessions were intensive and inclusive. Officers were told to look beyond the immediate concerns of their respective ministries and come up with solutions that cut across ministerial boundaries. The labs forced officers to adopt a holistic approach to policy problems that induced collaboration. The intensity of the lab sessions and the fact that the sessions lasted between six and eight weeks also gave officers sufficient material to appreciate the imperatives of collaborative work. The labs allowed them to view policy problems and prescriptions from multiple perspectives. To make for an effective collaborative effort and better policy prescription, participants were provided with views collated from the public from interviews, online feedback and text messaging (lyer 2011).

In the end, the labs became more than sites to develop tangible targets and mobilize resources from different government agencies; the labs became sites for stakeholders to bond and make a realistic assessment of each agency's strengths and weaknesses. In fact, participating officers admitted that the lab sessions trained them to decide on socially desired outcome from a collective standpoint. One officer from the Ministry of Transport mentioned that the incremental, piecemeal and collaborative approach adopted helped officers to develop a more holistic appreciation of the problem discussed.

The officer also mentioned that the tools employed by PEMANDU facilitated the collaborative process. During the sessions, participants were told to move from broad policy goals to more specific targets, a process that PEMANDU's CEO Idris Jala described as "going from 3,000 feet to 3 feet." This involved "starting with the big picture and sharpening the focus to inspect its smallest detail" (Iyer 2011, 6). To help them make specific targets, participants were told to adopt an iterative and recursive approach. This involved revisiting old assumptions, raising new information and reconfiguring earlier targets and plans (Sabel and Jordan 2015). PEMANDU officials were on hand to assist the process. Acting as facilitators they encouraged 
participants to start their propositions with a blank canvas and to revisit initial plans, which led to lively and open discussions among the participants. The whole process effectively induced collaborative tendencies as "participants come to know and trust one another, they bring to the fore, knowledge of problems or solutions that, at the outset, they may have held closely to themselves" (Sabel and Jordan 2015, 19).

For more effective collaborative work, participants in the lab sessions were made to present their detailed plans to senior officials from two key agencies - the Ministry of Finance (MoF) and the Economic Planning Unit (EPU) - for a more realistic assessment. Called the "stress test" the presentations were meant to impress on participants that policy plans would have to be weighed against the state's many priorities and resource limitations. The "stress test" sessions, which at times were attended by ministers, saw senior government officials querying participants on the rationale and details of their plans. After listening to the presentations, the senior officials would brief participants on the feasibility of the projects when measured against financial and administrative limitations. At the end of the sessions, modifications were made after participants weighed in on the various concerns.

Indeed, the social labs added to the collaborative process as they did away with hierarchical concerns, promoted lateral network settings and encouraged the co-creation of policy design. PEMANDU's adoption of the recursive and iterative approach to policy prescription and the informal nature of the lab sessions encouraged members to come up with new policy possibilities. They helped participants make realistic judgments of policies and forced them to look at issues from a multi-sectorial perspective that cut across ministerial concerns. The interactive dialogs and the iterative approach also helped in promoting buy-ins from stakeholders (Sabel and Jordan 2015, 32). In fact, the collaborative process saw 50 percent of original solutions be revised, and this was due to the new pieces of information raised by participants. One director of the education NKRA team said that the

lab is an environment where hierarchy is set aside. We encourage participants to leave their 'organisational hats' outside the door. It empowers civil servants, giving them a chance to voice ideas that may have been in the works for years (lyer 2011, 7).

But how much has PEMANDU's collaborative endeavor permeated the bureaucracy? Has collaborative governance become a central organizing principle in the conduct of Malaysian bureaucracy? To demonstrate the extent to which PEMANDU's processes and ideas on collaboration have pervaded bureaucratic thinking, we describe two examples. The first involves PEMANDU in a collaborative project with different agriculturally related agencies, and the second involves PEMANDU providing its expertise in setting up a "delivery unit" within a particular ministry that is tasked with promoting collaboration.

\section{PEMANDU and improving Paddy Productivity in the Muda Region}

The Muda Paddy project demonstrates the successes of as well as challenges to collaborative governance. The project involved the collaboration of several agencies - PEMANDU as the facilitator, the Ministry of Agriculture (MOA), the Muda Agricultural Development Authority (MADA) and the farmers' association called Persatuan Peladang Kawasan (PPK) - and aimed to improve productivity in paddy farming in the Muda region, a rice farming area in Northern Peninsular Malaysia. In fact, the Muda project was one of PEMANDU's many initiatives under its Entry Point Projects (EPP), projects whose aim was to turn traditional agriculture activity into 
agribusiness activity by incorporating the latest technology to improve output and earnings. There were in total 16 EPPs, and these projects involved existing farmers as well as new entrants and covered a range of agricultural activities - from seaweed farming, herbal production, farmed fishing, and livestock to rice production (Adnan and Nasirruddin 2016).

The Muda region paddy project was aimed to promote commercial-scale farming, improve irrigation density and accelerate the use of new technologies. The project attempted to do so by aiming to amalgamate some 50,000 hectares of paddy fields - about 51 percent of total paddy fields in the country - involving some 27,500 small-time farmers. The amalgamated land would then be run like a paddy estate and centrally managed by a private management entity. Under the scheme, paddy farmers were given the choice to either work their own land or lease their land to the management company, which would provide the labor. Either way, the management company would provide assistance by way of levelling the land and providing technical assistance to farmers, which includes activities like treatment of soil by controlling water and acidity levels. In return for the management assistance, farmers must agree to implement good agricultural practices, which involved precision in planting and harvesting, treatment of soil quality, efficient water use and pest control. Farmers who opted for the scheme were also trained to adopt the latest technologies, and this involved incorporating the latest knowledge across all paddy and rice production chains. They were also taught methods to improve irrigation density and they were introduced to large-scale farm mechanization. In choosing the scheme, farmers were given RM 10,000 per hectare as an incentive, and this is disbursed over 5 harvesting seasons.

The Muda region project intended to increase average yields to 8 tonnes per hectare and to increase farmers' annual income to RM 48,000 by 2020 from a current income of about RM 24,000 per annum in 2011. To ensure that targets were met, PEMANDU worked closely with the MoA and MADA to monitor the performances of the PPKs. The collaboration - between PEMANDU, MoA, and MADA - involved making sure that farmers kept to the proposed plan. Lands were inspected regularly by agricultural officers from the MOA and MADA. These officers followed the "rice check manual" to assess the performance of rice production and provided necessary feedback to farmers. PEMANDU's principles and processes were also incorporated in the project, and this came in the form of Standard Operating Procedures (SOPs), which were meant to ensure that farmers adhered to common best practices in farming methods and adopted new technologies. A chain of processes was also put in place that mirrors PEMANDU's delivery process. They include monitoring, problem-solving and learning (Sabel and Jordan 2015). In the collaborative effort, the PPKs acted as "delivery units" by performing the task of a conduit between PEMANDU, the Ministry of Agriculture and the farmers. These stakeholders would monitor their progress against the one set by PEMANDU. Indeed, the Muda project provided steep learning lessons for small farmers as it aimed to promote capacity-building, specifically improving local learning through self-monitoring. Thus far, a total of RM 2.7 billion had been invested in the Muda project, out of which RM 2.2 billion went to the intensification of irrigation infrastructure.

The World Bank Report (2011) describes the collaborative effort as "one of the most inventive and audacious of PEMANDU's reform undertakings" (Sabel and Jordan 2015, 37) given the magnitude of the amalgamation and the short time frame given to achieve the goals. Work, however, was still in progress as far as the amalgamation of land is concerned. There had been a setback in its implementation, which is discussed below. But overall, the results show that on average "participants' income rose by 11 percent and in the strongest performing PPKs yields rose to more than 20 percent" (Sabel and Jordan 2015, 38). 


\section{Setting up a PEMANDU-like agency within an agency}

Another project to demonstrate the extent of the incorporation of PEMANDU's delivery processes was the setting-up of a PEMANDU-like unit within the Ministry of Education. The "Performance and Delivery Unit" (PADU) is a unit within the education ministry that was tasked to carry out PEMANDU's "deliverology" philosophy to reform Malaysia's education policies. The unit's mandate involved taking charge of implementation and managing the interdependencies involving the different units in the education ministry to ensure ongoing improvements in providing quality education. On its website, PADU describes itself as a unit to "facilitate, support, and deliver the ministry's vision in transforming Malaysia's education system", specifically achieving the targets set out in Malaysia's national blueprint for 2013-2025. The unit also describes that it "collaborates with the ministry to develop remedial action plans."

The Ministry of Education sought PEMANDU's advice in setting up PADU. In its design, PADU mirrored PEMANDU's. Just like PEMANDU, PADU was headed by a chief executive officer who had some years of working experience in the private sector. PADU's CEO was aided by seven executive directors. When it came to policy delivery, PADU incorporated PEMANDU-like processes, for instance having PEMANDU-like dashboard indicators to measure the performance of individual units and carrying weekly meetings involving PADU'S CEO and other stakeholders. But unlike PEMANDU's case - where its CEO held weekly meetings with the Prime Minister and cabinet ministers - PADU's weekly meetings involved its CEO, the second education minister and the various heads of units to discuss the progress made.

In delivering its targets, PADU worked closely with the various units in the education ministry as well as with various state education departments. One project involved PADU organizing a collaboration effort among senior education officers in the state of Perlis. Working closely with Perlis' state education department (Jabatan Pelajaran Negara (JPN)) PADU officials held a series of consultations and in-depth interviews with the state education officers to help them identify the difficulties and roadblocks they faced in achieving the National Education Blueprint and in overcoming Perlis' poor national examinations scores. The meetings with the education officers involved reflection sessions. These were similar to PEMANDU's social labs, but this time, it involved PADU officials, who aided the discussions by orienting participants to deliberate on issues of high impact that would affect performance delivery. At the end of the sessions, officers identified four key success factors in driving change - collaboration among JPN officers, school leadership, quality teaching and learning in the classroom and student attendance - which were then translated into actionable items. PADU's sessions with the Perlis education officers produced results. In its 2015 annual report, the Ministry of Education detailed how the collaborative efforts between schools in Perlis saw the state recording its biggest improvement in the national primary-school examination in 2015. An interesting point to note is that when describing PADU's work, the report makes heavy use of vocabulary like "maximum impact", "success factors", "actionable items", "targeted intervention" and "quick wins", vocabulary that is often used by PEMANDU to describe its processes. Indeed, the words reflect PADU's attempt to emulate the inner workings of PEMANDU.

The two cases - the Muda Paddy Project and PADU - provided contrasting aspects of collaborative governance. In the end, the two projects gave mixed results, indicating that collaborative governance is never isomorphic. The two examples depicted invite obvious concerns: what are the essential features for collaborative governance to work in Malaysia, and could collaborative governance be an institutionalized feature of the Malaysian bureaucracy? We elaborate this below. 


\section{Whither collaborative governance?}

The details above underlined the essential features of Malaysia's collaborative process. PEMANDU's unique operational positioning in Malaysian bureaucracy - the autonomy to manage its resources, easy access to the chief executive, the ability to employ sophisticated and idiosyncratic techniques in promoting collaboration tailored to the bureaucratic culture and the ability to organize various social labs - all had the right formula to make for a successful collaborative project. However, the two cases demonstrate that it takes more than just the above qualities to make for the successful execution of collaborative governance. What was clearly missing from the equation were the issues of trust and legitimacy.

Malaysia's introduction of collaborative governance was more of a project initiated by the state to improve governance and restore trust and legitimacy to the then ruling regime after the regime suffered a huge drop in popularity in the 2008 and 2013 general elections. Trust in government initiatives was clearly low. Such was the extent of the trust deficit and legitimacy problems that then Prime Minister Najib Abdul Razak remarked that "I must execute [government and economic transformation programmes] or be executed" (Comin and Peng 2012). He also remarked that "his future and that of his government is in jeopardy unless public frustration with the poor state of service delivery and other governance issues are tackled urgently" (Siddiquee 2014, 25).

In spite of the World Bank's impression of PEMANDU as having the best arrangement for collaborative governance, the Muda region paddy project and PADU demonstrate that issues of trust and legitimacy remain a huge challenge to successful collaborative governance. Indeed, the two cases indicate that the institutionalization of collaborative governance remains in doubt due to issues of trust and legitimacy. The Muda region paddy project and PADU showed that a trust deficit fostered public apathy and non-cooperation that saw citizens prefer to be passive participants in the public-policy process. The psychological contract between the governed and the government - manifested by way of trust and legitimacy in government - were absent, which made the collaborative endeavor a challenge. The lack of trust was demonstrated from farmers' unwillingness to amalgamate land despite the project reporting an increase in national rice sufficiency from 63 percent in 2010 to 71 percent in 2015 (National Transformation Programme Report 2015, 284). In fact, PEMANDU's employment of the stateof-the-art management rubric to encourage collaboration among farmers was not enough to convince farmers of the benefits of economies of scale that could be reaped from land amalgamation. Farmers were not enthused by the project despite seeing their income improve and yields increase. Some who joined the scheme opted out after they no longer enjoyed the financial incentive of RM 2,000 per hectare after five seasons. For non-amalgamated farmers there were no reasons to join the project after they saw their yields increase from using new technology. Only 20,000 hectares of land were amalgamated in 2015 , and this is 40 percent of the target of 50,000 hectares to be reached by the year 2020 (Adnan and Nasruddin 2016).

Trust and legitimacy deficit issues were alluded to in PEMANDU's annual report. In the report PEMANDU acknowledged the administrative challenges to the implementation of the Muda paddy project, highlighting the difficulty in persuading farmers to employ best practices and urging farmers to use new technologies. The report also mentioned that despite MADA's (Muda Agricultural Development Agency) effort at introducing standard operating procedures (SOPs), not all farmers "enjoyed these benefits [higher income] as they did not implement the SOPs" (Pemandu 2016, 241). In another statement that underlines issues of trust and legitimacy, 
PEMANDU also mentioned problems in constructing irrigation infrastructure because of the issue of land acquisition with farmers, citing legal and administrative problems. The lack of enthusiasm on the part of farmers was also reflected when PEMANDU admitted that it was putting on hold the introduction of a special purpose vehicle to manage the industry's entire value chain because the "state of operational readiness is yet to be established", which, the report admitted, could "hinder fruitful collaboration" (Pemandu 2016, 241). It is indeed a tragedy that efforts at collaborative governance that are so necessary for dealing with an increasingly complex system are impeded by political imperatives and deep mistrust in institutions.

The projects demonstrate both the huge potential that can be reaped from the collaborative effort and the amount of work needed to institutionalize collaborative governance. Institutionalizing collaborative governance remains. PEMANDU ceased operations in May 2018, days after Malaysia experienced a change of government. The Barisan Nasional (BN), who had ruled Malaysia for 61 years, lost its hold of power. This new chapter in the country's political history naturally saw the newly installed government making it clear that it would do away with major projects of the previous government. Given that the collaborative-governance project is nested within Malaysia's larger development goals designed by the previous regime, there is little to believe that collaborative governance, in the manner that it is carried out now, will continue. The newly installed government had made known during its campaign trail that it would remove PEMANDU, which it did, saying that PEMANDU had failed to deliver in its main Key Performance Indicators, failed to be accountable to parliament and had ensnared itself in possible conflict-of-interest situations. PEMANDU is now a private consultancy firm called PEMANDU Associates. The firm has retained the original name for reasons of goodwill and the track record that PEMANDU had garnered over the years.

Can there be an alternative unit that can replicate PEMANDU's role as a collaborative agent? This would be difficult mainly because PEMANDU's unique organizational design had provided it with the ability to deliver collaborative performance between various stakeholders. Its special position in the bureaucracy - its direct access to the prime minister, its independence in terms of recruiting the best from the private sector, its attractive remuneration packages that are outside the civil-service pay structure - was path-breaking, as far as Malaysia's administrative arrangement is concerned. PEMANDU's unique positioning within the bureaucracy provided it with sufficient power to convene the different stakeholders (Huxham and Vangen 2000b). Such a positioning had provided PEMANDU with greater latitude to manage its agenda and not be bound by institutional compliance expected of a public bureaucracy. To appreciate PEMANDU's unique value proposition - its organizational design and mandate - one only needs to compare PEMANDU's ability to effect change with that of PADU, the unit that attempts to mirror PEMANDU. PADU could not produce the same collaborative arrangement with its stakeholders as PEMANDU had done. What is missing from PADU's delivery process is the direct access to the top leadership, the Prime Minister or even the Minister of Education; PADU'S CEO reports to the Second Minister of Education, not to the Prime Minister or the Minister of Education. PADU's position within the hierarchy also makes the execution of collaborative work a challenge. Hierarchy-wise, PADU is one of 37 units in the ministry, so despite assuming the position of Chief Executive Officer, PADU's chief is of similar rank and authority as other department heads. This limited span of control in the organization and its embeddedness within the ministry of education and the civil-service structure are PADU's Achilles heel. It is hard for PADU to be a facilitator for change because Malaysia's 
bureaucratic politics, cultural code, and presence of high power distance - where grades and positions define the individual's mandate or scope of work - could result in occasions when heads of departments would refuse to take the advice of PADU officers who are of lower rank. In their assessment of PADU's performance, officers in the education ministry expressed doubts about PADU's ability to deliver the education blueprint. One of the officers we talked to raised the concern that PADU directors were new recruits to the civil service with little or no background in educational services. The officers expressed the assumption that the new PADU recruits might not know much of on-the-ground operations. They also expressed concern that PADU is a small unit and that it may be overwhelmed by the scale of the blueprint. PADU's inherent challenges to institute change are not unlike the experience of many change agencies within the Malaysian bureaucracy. One case in point was the challenges faced by Malaysia's Administrative and Modernisation Planning Unit (MAMPU), an agency that is tasked with carrying out administrative reform. Taking the view of Malaysia's bureaucratic code, MAMPU officers were not able to initiate change because they are still guided by the fear that a perceived act of insubordination would jeopardize their promotional prospects (Noh and Tumin 2013,97). There is, of course, the possibility to replicate PEMANDU's role in the civil service, but without PEMANDU's unique line of authority, there is a possibility of conflicting agency goals and missions, inflexible administrative and legal procedures and constrained financial resources (Purdy 2012). Indeed, a diffuse authority structure can hamper the collaborative process because it affects the extent of participation, cooperation, and representation (Huxham and Vangen 2000a). PEMANDU's organizational arrangement had proven to be critical in obtaining buy-ins and mobilizing collaboration. One officer we interviewed, who was a special officer to a minister, mentioned how one critical government agency "dropped everything in their path" to give priority to PEMANDU-led initiatives every time there was a visit by PEMANDU officials.

\section{Conclusion}

This article describes the collaborative process as well as highlights that understanding the process remains a challenge. In its attempt to circumvent the difficulty of understanding the collaborative process it has adopted a second-best method, that is, by using an important change agent as a prism to observe the collaborative process.

What are some of the lessons that can be drawn from PEMANDU's collaborative process? One obvious take away is the importance of organizational design. While it is true that PEMANDU fell short of its objectives, its organizational design is worth noting. PEMANDU's organizational design is hard to replicate. PEMANDU's positioning in Malaysian bureaucracy was unprecedented in Malaysia's administrative history; a unit within the Malaysian bureaucracy, yet it did not exactly operate like other agencies within the bureaucracy. In the initial years, its CEO was appointed a senator in the upper house and made a cabinet minister. This arrangement allowed PEMANDU the autonomy to recruit personnel, the ability to plan for its own budget, the privilege of having direct access to the Prime Minister and the ability to liaise directly with ministers and the different ministries - factors that facilitated collaboration. The case of social labs, the cabinet workshop and the adoption of various bureaucratic mechanisms to ensure better delivery are some of the examples of how PEMANDU's organizational design facilitated the collaborative process. It must be said, however, that PEMANDU's organizational design is not without its risks. Its ready access to public funds, its close nexus with the highest 
political authority, its autonomy when it comes to operation suggests the need to put in place safeguards to protect the public good. Without such safeguards, this organizational design can easily succumb to governance issues of accountability, conflict of interest and abuse of power, which ultimately affects the perception of governance and costs the regime its legitimacy.

A second lesson that can be drawn from PEMANDU's experience is the importance of buy-ins from key actors in policy execution. By putting in place mechanisms to convince important actors of policy objectives, obtaining buy-ins from key appointment holders in government would result in lesser resistance and avoid policy distortion. A case in point is the workshop for cabinet ministers. PEMANDU's organization of the workshop was difficult but one that was completely important; without the buy-ins from the ministers PEMANDU's collaborative endeavor would have faced greater resistance from the bureaucracy. This is especially relevant in high power-distance settings, like Malaysia. In a place where hierarchy and positions are viewed as important qualities to execute policy successfully, having the cabinet ministers promote difficult policies was indeed crucial. Also, the heavy presence of the prime minister was helpful at the initial stage because it sent signal to ministers on the seriousness of the workshop and the importance of greater collaboration.

PEMANDU's employment of the blind voting system also needs mentioning. The blind voting system fits a Malaysian bureaucratic culture that is high on collectivism. In a setting where bureaucrats tend to display in-group cohesiveness, indulge in collective action and promote "perverse equalitarianism", where members tend to stick to a conformist culture for fear of being too direct, insensitive or rude, the blind voting system gave members the security that their views would be held in confidence. Indeed, PEMANDU's blind voting system was a novel idea, a clever way of negotiating Malaysia's bureaucratic structure and culture to get optimum policy outcomes.

PEMANDU's collaborative design in settling disputes and resolve bottleneck issues also stands out. Such mechanisms at dispute settlement came from an appreciation of a bureaucratic culture that is not naturally predisposed to inter-ministerial collaboration. PEMANDU's incorporation of group dynamic techniques that took into account bureaucrats' "facesaving" or "avoidance of group conflict" tendencies eased inter-ministerial interactions and produced collaborative tendencies between bureaucrats.

But the Malaysian experience also highlights many concerns. The first is that the design and performance of collaborative governance remains a function of the state-society structure. As the World Bank report pointed out, it is hard to replicate the Malaysian experience because PEMANDU was designed and executed in the context of Malaysia's state-society structure. Second, state-initiated collaborative design may not be enough for a successful collaborative exercise. The state's heavy involvement in the collaborative design and the state's nurturing of an ecosystem to facilitate the collaborative process is necessary but not sufficient to make for successful collaborative governance. The Muda Project and PADU show that although there were small wins in the collaborative process, these were not enough to remove the more systemic issue of trust deficit and lack of legitimacy for the ruling government. Indeed, the examples showed that issues of trust, legitimacy and regime coherence could throw off the best collaborative organizational design and state's intentions. Trust and regime legitimacy can interfere with ideas of shared motivation and collaborative governance. The Malaysian example demonstrates that trust, legitimacy and regime quality are important, perhaps 
necessary, to make collaborative work. Such loss of legitimacy was ultimately reflected in May 2018, when the then ruling regime lost its hold of power for the first time in 61 years.

This article does not pretend to present a formula for collaborative governance. Rather, the article only raises a lot more questions than it answers. While the likes of Ansell and Gash (2008) and Emerson et al. (2012) provide parsimonious models that have included various factors that are important to the collaborative process, the process of instituting collaborative governance does not come in neat packages. This article demonstrates that understanding the collaborative process remains a huge challenge due to the multitude of considerations.

\section{References}

Adnan, M.N. and A. Nasiruddin. 2016. "Transiting from Agriculture to Agribusiness: A Model for Inclusivity and Sustainability for Paddy farmers." Second World Irrigation Forum, Chiang Mai, Thailand.

Ansell, Chris. 2012. "Collaborative Governance." In David Levi-Faur (ed.). The Oxford Handbook of Governance. Oxford: Oxford University Press, 498-511

Ansell, Chris and A. Gash. 2008. "Collaborative Governance, in Theory, and Practice." Journal of Public Administration Research and Theory 18(4), 543-571.

Ansell, Chris, E. Sorensen and J. Torfing. 2017. “Improving Implementation through Collaborative Policy Making." Policy and Politics 45(3), 467-486.

Ansell, C. and J. Torfing (eds). 2014. Public Innovation through Collaboration Design. Vol. 19. New York. Routledge.

Bardach, Eugene. 1998. Getting Agencies to work together: The Theory and Practice of Managerial Craftsmanship. Washington D.C. Brookings Institutions Press.

Chrislip, David and Carl E. Larson. 1994. Collaborative Leadership: How Citizens and Civic Leaders can Make a Difference. San Francisco, CA: Jossey Bass.

Comin, Diego A. and Ku Kok Peng. 2012. "Malaysia: The Economic Transformation Program." Harvard Business School Supplement 713-008, September 2012.

Currie, G., S. Grubnic and R. Hodges. 2011. "Leadership in Public Services Networks: Antecedents, Process, and Outcome." Public Administration 89(2), 242-264.

Dorf, Michael C. and Charles F. Sabel. 1998. "A Constitution of Democratic Experimentalism." Cornell Law Faculty Publications 120.

Emerson, K., T. Nabatchi and S. Balogh. 2012. “An Integrative Framework for Collaborative Governance." Journal of Public Administration Research and Theory 22(1), 1-29.

Emerson, K. and T. Nabatchi.2015a. Collaborative governance regimes. Washington DC. Georgetown University Press

Emerson, K and T. Nabatchi. 2015b. Evaluating the Productivity of Collaborative Governance Regimes: A Performance Matrix. Public Performance and Management Review 38(4), 717747

Fung, Archon. 2004. Empowered Participation: Reinventing Urban Democracy. Princeton, NJ: Princeton University Press.

Fung, A. 2003. “Recipes for Public Spheres: Eight Institutional Design Choices and Their Consequences." Journal of Political Philosophy 11(3), 338-367.

Gray, Barbara. 1989. Collaborating: Finding Common Ground for Multiparty Problems. San Francisco: Jossey Bass.

Hill, M. and P. Hupe. 2014. Implementing Public Policy. London: Sage.

Hofstede, G. 1980. Culture's Consequences: International Differences in World-Related Values. London: Sage Publications. 
Hui, W.S., Othman R. Omar, N.H. Rahman and N.H. Haron. 2011. “Procurement Issues in Malaysia." International Journal of Public Sector Management 24(6), 567-593.

Huxham, Chris. 2003. “Theorising Collaboration Practice.” Public Management Review 5, 401423.

Huxham, Chris and S. Vangen. 2000a. "Leadership in the Shaping and Implementation of Collaboration Agendas: How Things Happen in a (Not Quite) Joined-Up World." Academy of Management Journal 43(6), 1159-1175.

Huxham, Chris and S. Vangen. 2000b. “Ambiguity, Complexity, and Dynamics in the Membership of Collaboration." Human Relations 53(6), 771-806.

Innes, Judith E. and David E. Booher. 1999. “Consensus Building as Role Playing and Bricolage: Toward a Theory of Collaborative Planning." Journal of the American Planning Association 65(1), 9-26.

Iyer, Deepa. 2011. Tying Performance Management to Service Delivery: Public Sector Reform in Malaysia, 2009-2011. Princeton University. Available at https://successfulsocieties. princeton.edu/publications/tying-performance-management-service-delivery-publicsector-reform-malaysia-2009-2011 (last accessed on 04 November 2019)

Kennedy, J. and N. Mansor. 2000. Malaysian Culture and the leadership of Organisation: A Globe Study. "Malaysian Management Review" 35(2), 42-53.

McGuire, M. 2006. "Collaborative Public Management: Assessing what we know and how we know it." Public Administration Review 66, 33-45.

Meier, K. and J. Bohte. 2007. Politics and Bureaucracy. Belmont. MA. Wadsworth Publisher.

Newman, Janet, Marian Barnes, Helen Sullivan, Andrews Knops et al. 2004. “Public Participation and Collaborative Governance." Journal of Social Policy 33(2), $2013-2223$.

Noh, Abdillah and Tumin. M. 2013. Institutions and Institutional Change: The Case of the Malaysian Bureaucracy. Man and Society. 23.

Pemandu. 2016. National Transformation Programme (NTP): Annual Report 2015, Kuala Lumpur, Prime Minister Officer, Government of Malaysia

Purdy, Jill. 2012. "A Framework for Assessing Power in Collaborative Governance Processes." Public Administration Review 72(3), 409-417.

Ramadass, Shila et al. 2018. “Collaboration Outcomes in a Public Sector: Impact of Governance, Leadership, Interdependence and Relational Capital." Journal of Management and Governance 22, 749-771.

Reilly, Thom. 1998. “Communities in Conflict: Resolving Differences through Collaborative Efforts in Environmental Planning and Human Service Delivery." Journal of Sociology and Welfare 25, 115-142.

Ring, Peter Smith and Andrew H. Van de Ven. 1994. “Development Process of Cooperative Interorganisational Relationship." Academy of Management Review 19(1), 90-118.

Ryan, Claire. 2001. “Leadership in Collaborative Policymaking: An Analysis of Agency Roles in Regulatory Negotiations." Policy Sciences 34, 221-245.

Sabel, C. and Luke Jordan. 2015. Doing, Learning, Being: Some Lessons Learned from Malaysia's National Transformation Program'(English). Washington D.C.: World Bank Group. Available at http://documents.worldbank.org/curated/en/464231565116506887/ Doing-learning-being-some-lessons-learned-from-Malaysias-national-transformationprogram (last accessed 04 November 2019)

Sabel, C.F. and J. Zeitlin. 2008. "Learning from Difference: The New Architecture of Experimentalist Governance in the European Union." European Law Journal 14, $271-327$.

Siddique, N.A. 2007. “The Government Transformation Programme in Malaysia: Recent Initiatives and experiences." International Journal of Public Sector Management 19(4), 339-358.

Siddiquee, N.A.2014. Malaysia's Government Transformation Programme: A Preliminary Assessment. Intellectual Discourse 22(1), 7-31

Thomson, Ann Marie and James Perry. 2006. “Collaboration Processes: Inside the Black Box." Public Administration Review, December, Special Issue. 
Thomson, A.M, J.L. Perry and T.K. Miller. 2007. "Conceptualising and Measuring Collaboration." Journal of Public Administration Research and Theory 19(1), 23-56.

Wood, D. and B. Gray. 1991. "Collaborative Alliance: Moving from Practice to Theory." Journal of Applied Behavioral Science 27(1), 3-22.

World Bank. 2017. Driving Performance from the Centre, Malaysia's Experience with PEMANDU. Washington: World Bank Group.

Xavier, John Antony, Noore Alam Siddique and Mohd Zin Mohamed. 2016. "The Government Transformation Programme of Malaysia: A Successful Approach to Public Sector Reform." Public Money and Management 36(2), 81-87.

Abdillah Noh is an Associate Professor at the Department of Political Science, International Islamic University Malaysia (IIUM). He works in the areas of institutional change, public administration and public policy. Abdillah has a DPhil (Politics) from St Antony's College, University of Oxford.

Nadia Yashaiya is a PhD candidate at the University of Western Australia. Her research focuses on public management, with an emphasis on employee job motivation, socialisation and public service motivation. 
